\title{
Single-Polymer Composites: Concepts, Realization and Outlook: Review
}

\author{
József Karger-Kocsis* \\ Department of Polymer Engineering, Faculty of Mechanical Engineering, Budapest University of Technology \\ and Economics, Müegyetem rkp. 3., Budapest H-1111, Hungary \\ MTA-BME Research Group for Composite Science and Technology, Müegyetem rkp. 3., Budapest H-1111, \\ Hungary
}

\section{Suchart Siengchin}

Materials and Production Engineering Department, The Sirindhorn International Thai-German Graduate School of Engineering (TGGS), King Mongkut's University of Technology North Bangkok, 1518 Pracharat 1 Road, Bangsue, Bangkok 10800, Thailand

* Corresponding author. E-mail: karger@pt.bme.hu

Received: 21 November 2013; Accepted: 12 December 2013; Published online: 27 January 2014

DOI: $10.14416 /$ j.jjast.2014.01.002

\begin{abstract}
Manufacturing, properties and applications of single-polymer composites (SPCS) have been surveyed. SPCs composed of amorphous or semicrystalline matrices and semicrystalline reinforcements were only considered because of their present and future relevance. Various concepts to enlarge the temperature difference between the matrix- and reinforcement-giving materials were listed and those applied commercially were discussed. The development of SPCs is fueled by the demand for various products which have low density and "ultimate" recyclability, namely reprocessing via remelting. At present SPC, parts are mostly used in the automotive, and sport/leisure sectors. Research activities target the production productivity, novel shaping technologies of SPCs, and ensuring their multifunctionality.
\end{abstract}

Keywords: Single polymer composites, Production, Interphase

\section{Introduction}

Great research efforts are undertaken to produce lightweight, easy reprocessable all-polymeric composites and especially single-polymer composites (SPCs). SPCs are also referred to self-reinforced, single-phase, homogeneous, mono-material, homogeneity or homocomposites in the open literature. Next we shall prefer the term singlepolymer composite (SPC) because it is becoming more and more accepted. In SPCs both the matrix and reinforcement are of the same polymer or of polymers belonging to the same family. The SPC term contradicts to the traditional definition of composite materials referring to a combination of chemically different materials in which one component acts as reinforcement while the other for the embedding matrix. On the other hand, basic characteristics (stiffness, strength) of the reinforcing component differ from those of the matrix in SPCs, as well. The reinforcement is highly anisotropic, whereas the matrix is usually of isotropic nature. A further similarity to traditional composites is that the reinforcements are also fibers, tapes and different textile assemblies in SPCs. SPCs and related materials have already been topics of reviews [1-5]. The aim of the present one is to give a brief, concise overview on the concepts, realization and future trends of SPCs.

The concept of SPC has to be credited to Capiati and Porter who made the pioneering work in this field in 1975 and denoted their material as "one polymer composite" [6]. The working principle of SPC is identical with that of traditional composites, i.e. stress transfer from the "weaker" matrix to the "stronger" 
reinforcement via the interphase. As semicrystalline polymers show always higher stiffness and strength than amorphous ones, they work exclusively as reinforcement. Matrices may be either amorphous or semicrystalline polymers. The interphase in SPCs is usually given by crystalline superstructures ensuring good adhesion and thus efficient stress transfer between the reinforcement and matrix. This is one of the great advantages of SPCs over traditional composites containing glass, carbon, aramid or natural fibers and related assemblies as reinforcements. Note that in traditional composites the necessary wetting of the fibers and their adhesion to the matrix are achieved by suitable sizing and coupling agents. The other beneficial properties are: low density and "ultimate" recycling through remelting. SPCs may compete with traditional composites in various application fields based on their favored recycling and beneficial performance/cost balance. This is the main reason for the industrial and commercial interests behind the SPCs' development.

\section{Concepts of SPC Preparation}

It is obvious that the major task when producing SPCs is to widen the temperature range between the matrix and reinforcement with respect to their softening (when the matrix is amorphous) and melting (when both matrix and reinforcements are semicrystalline). This is inevitable to minimize the loss in the mechanical properties of the reinforcement. Deterioration of stiffness and strength occurs via thermally induced shrinkage and partial melting which are accompanied with substantial changes in the morphology, and especially in that of the interphase.

Moreover, the processing parameters (heating/ cooling rates, pressure regime applied) are all timedependent which also strongly influence the degree of the property deterioration of the reinforcement and thus the performance of the consolidated SPC. Therefore it is imperative to widen the processing window. The latter may occur by exploiting some intrinsic features of the corresponding polymers and/or by choosing adequate processing methods and conditions.

\subsection{Matrix-related aspects}

Effects of molecular weight (MW) on the SPC performance are rather unclear. It is usually accepted that low molecular weight and low polidispersity support the wetting. However, they may have a negative impact on the interphase [7].

Many polymers, especially thermoplastic polyesters, tend for slow crystallization due to slow self-nucleation. They can be produced in fully amorphous form via fast cooling, i.e. quenching from the melt. Above their glass transition $\left(\mathrm{T}_{\mathrm{g}}\right)$ and below their melting temperature $\left(\mathrm{T}_{\mathrm{m}}\right)$ these materials undergo cold crystallization. Their fusing and crystallization are running parallel above a given temperature between $T_{m}$ and $T_{g}$ when heating from ambient temperature. This can be exploited by sandwiching crystalline reinforcements (film, fabric) in between amorphous films followed by hot pressing. This concept has been proved on examples of polyethylene terephthalate (PET) [8] and polylactic acid (PLA) [9]. Also the well-known undercooling phenomenon may serve as base for SPC production. Recall that undercooling means that the crystallization temperature $\left(T_{c}\right)$ is well below that of $T_{m}$. Accordingly, the reinforcement can be introduced into an undercooled melt in a two-step process, as recently demonstrated on example of polypropylene [10]. Recent process developments, such as Rocktool ${ }^{\circledR}$, may be in favor of such production routes.

In in situ polymerizable systems, polymerization is associated with crystallization from an undercooled melt. This is the case with in situ polymerization of cyclic butylene terephthalate (CBT) oligomers [11]. So, again the difference between $\mathrm{T}_{\mathrm{m}}$ and the crystallization temperature $\left(\mathrm{T}_{\mathrm{c}}\right)$ may be used in liquid composite molding (LCM) techniques to prepare SPCs. In situ polymerization has several advantages. The melt viscosity of the polymerizing system is very low, sometimes orders of magnitude lower than the usually accepted threshold for LCM operations, given by 1 Pas [12]. This is very helpful to achieve a complete wet-out of the reinforcing structure. A further benefit is that the polymerization may occur well below the melting temperature of the final polymer. This has been emphasized for CBT and holds also for other systems, like PA6, polymerized via activated anionic polymerization of $\varepsilon$-caprolactam $[13,14]$. Note that that polymerization below $\mathrm{T}_{\mathrm{m}}$ of the final polymer is accompanied with crystallization (undercooled melt). Nowadays there is a vivid interest to produce PA6based SPCs by this technique because robust catalyst/ activator systems became recently available $[15,16]$. 
Many polymers contain an asymmetric or stereogenic carbon atom in their chains meaning that a carbon atom is bonded to four different entities. They are termed to steroregular polymers. Just one example: polypropylene (PP) exists in two steroregulars, namely: isotactic (iPP; all methyl groups at the same side) and syndiotactic (sPP; methyl groups alternatively at either side of the planar zigzag-form chain), and one stereo-irregular form. The latter is the atactic PP (aPP; with sterically random oriented methyl groups). iPP and sPP are crystalline owing to their highly regular chain conformations. The melting temperature of sPP $\left(\mathrm{T}_{\mathrm{m}} \sim 135^{\circ} \mathrm{C}\right)$ and $\mathrm{iPP}\left(\mathrm{T}_{\mathrm{m}} \sim 165^{\circ} \mathrm{C}\right)$ are, however, different. Therefore, it seems to be a straightforward approach to use atactic polymer for the matrix while its stereoregular crystalline versions for the reinforcement. Recall that the atactic or amorphous polymer softens far below the melting temperature of the crystalline forms. This approach is especially appealing for the matrix/ reinforcement combination atactic polystyrene (aPS)/sPS.

Exploiting the polymorphism of semicrystalline polymers is another possibility. Polymorphis means that a polymer exists in more than one crystalline form. iPP for example exists in four different crystalline modifications $(\alpha, \beta, \gamma, \delta)$ with different crystal unit (monoclinic, hexagonal, triclinic and pseudo hexagonal lattices, respectively) cell parameters owing to various packing of the chains [17-19]. However, not all of the crystalline forms are stable. Some of them are metastable undergoing a phase transition toward the more stable version upon heating or other external stimuli. The most important feature of polymorphism is that these crystalline modifications possess various $\mathrm{T}_{\mathrm{m}}$ data. Their difference may be very useful to expand the processing window for SPC production provided that the, metastable" versions, having lower melting temperatures than the stable ones, can be produced with high selectivity. This concept has been introduced by KargerKocsis on example of $\beta$-PP(matrix) $/ \alpha$-PP(reinforcement) [20]. This was facilitated by the fact that highly selective $\beta$-nucleants are nowadays available for iPP [21].

Crystallinity and crystallization-related features have been widely used to enlarge the temperature range of SPCs' processing. In general, all semicrystalline polymers contain crystallites with different perfections. As a consequence, the crystallites have different melting temperatures and the corresponding polymer has a quite broad melting range. Like to crystallization, the melting is also characterized by temperatures linked to the onset, maximum and final melting. Temperatures in the vicinity of melting onset are well suited to produce SPCs. This is the principle of hot compaction during which the surface of the reinforcing structure is melted and transferred into the matrix [22-23].

A further possibility to tailor the $\mathrm{T}_{\mathrm{m}}$ is the molecular architecture. This cover chain branching, co- and terpolymerization processes, as well. The extent and density of the branches, by whatever means generated, have a strong impact on the crystallization, crystallinity and also on the melting of the related products. Let us consider the melting range of polyethylenes (PEs) that is increasing according to the ranking: low density (LDPE, $\mathrm{T}_{\mathrm{m}} \sim 110^{\circ} \mathrm{C}$ ) < high density (HDPE; $\mathrm{T}_{\mathrm{m}} \sim 130^{\circ} \mathrm{C}$ ) < ultra high molecular weight (UHMWPE; $\mathrm{T}_{\mathrm{m}}^{\mathrm{m}} \sim 135^{\circ} \mathrm{C}$ ). LDPE contains long side chains in high density which are practically absent in UHMWPE. The temperature difference, that can be guaranteed based on the above $\mathrm{T}_{\mathrm{m}}$ data, is sufficient enough for the production of two-constituent SPCs, such as LDPE (matrix)/HDPE (reinforcement), HDPE (matrix)/ UHMWPE (reinforcement). Note that in the latter system the MW is also of importance. Such PE combinations were explored in the early stage of the history of SPCs.

Copolymerization makes the macromolecular chain less regular. So, the crystals formed are less perfect and they melt at lower temperature compared to the corresponding homopolymer. The related temperature difference may be large enough for SPC preparation. The copolymer is always the matrix giving component. The matrix giving copolymer can be incorporated separately (in forms of fibers, films - via hot pressing and film stacking) or combined with the reinforcement in forms of suitable preforms (coextruded tape, core-shell type bicomponent fiber, cocarding and comingling of co- and homopolymer-based fibers). Techniques yielding core/shell type bicomponent fibers and tapes are especially straightforward because the reinforcement content of these performs may be very high, up to ca. $90 \mathrm{wt} \%$. Highly stretched copolymer-coated iPP tapes under the trade name Pure ${ }^{\circledR}$ have been marketed by Lankhorst Indutech (The Netherlands) [24].

\subsection{Reinforcement-related aspects}

As reinforcements of SPCs fiber and tapes, also in different assemblies and textile structures, are exclusively 
used. They have to exhibit high Young's modulus and strength. These properties are achieved by spinning (melt, wet, dry, gel), solid-state drawing (continuous, discontinuous; one-step, multi-step; zone drawing etc.) or by their combination (e.g. melt extrusion followed by in line drawing in several steps at different temperatures). The final aim is to get highly oriented fibers and tapes with high degree of crystallinity. The desired structure and properties can be guaranteed by selecting suitable polymers (MW, polydispersity, melt flow rate...) and proper production conditions (e.g. drawing temperature, rate, ratio...). Due to the crystalline superstructure of the spun and stretched fibers, tapes and related products, they show higher $\mathrm{T}_{\mathrm{m}}$ than the same polymer crystallized in quiescent melt [25] which is beneficial for the production of SPCs. For their applications in SPCs it is straightforward to stabilize them, i.e. to reduce their temperature-induced shrinkage/relaxation. This may happen by heat setting, crosslinking and also by incorporation of nanofillers (silica [26], layered silicate, carbon nanotubes [27]). Fibers and tapes may be assembled in different forms and methods as shown later.

Highly oriented nanoscaled fibers, usually in mat form, can be produced by solution or melt electrospinning. Micro- and nanofibrils can be created also by making use of the microfibrillar composite concept proposed by Fakirov [28].

There is another processing-related aspect, which plays an important role in SPCS: $\mathrm{T}_{\mathrm{m}}$ of the spun or stretched fibers, tapes can be further enhanced when heated in constrained form [25, 29]. This phenomenon, termed to overheating, impedes the relaxation of fibers and tapes and yields a $\mathrm{T}_{\mathrm{m}}$ increase of around $10^{\circ} \mathrm{C}$. The broad crystalline melting peak along with this overheating phenomenon are the base of hot compaction (see later) invented by the group of Ward ([22-23] and references therein).

\subsection{Matrix/reinforcement interface}

Recall that the matrix and reinforcement in SPCs are chemically identical. Therefore it is widely surmised that the usual problems linked with wetting and adhesion of the reinforcement by the matrix are less severe. The reader will easy recognize next why this claim is not fully correct. In their pioneering work Capiati and Porter [6] called the attention to the appearance of a transcrystalline layer (TC). This formed between

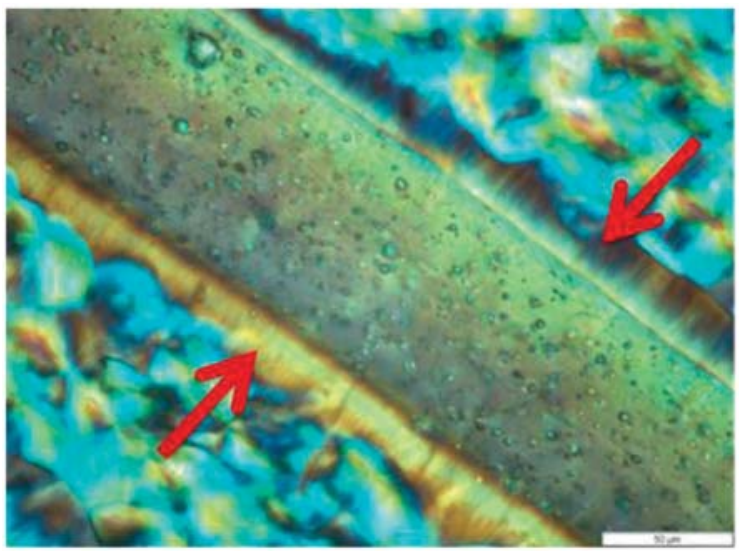

Figure 1: TC layer in a PP-based SPC.

the reinforcing fiber and matrix resulting in a strong interphase of gradient structure. Transcrystallization is caused by heterogenous nucleation provided that the nucleating surface possesses active nuclei in high density. Owing to the dense nucleation the lateral growth of spherulites is impeded and they are forced for a one-directional growth transverse to the nucleant's surface-cf. Figure 1. The controlling factors of transcrystallization and the effects of TC layer on the mechanical properties of the related composites are still topic of scientific debate [17, 30-31]. It is, however, generally accepted that transcrystallization is caused by epitaxial overgrowth [32]. Accordingly, the nucleating surface is crystalline and its crystalline structure should be matched with that of the growing crystals from the melt. This prerequisite is always met in SPCs with semicrystalline matrices. The interfacial phenomena in SPCs were rarely addressed by researchers. The onset of TC layer does not necessarily yield improvement in the interfacial transverse and shear stresses.

Only few papers delivered further insight in the TC morphology and related effects on the SPCs' mechanical performance. This is, however, a key issue deserving focused attention. It is well known the thickness of the TC layer strongly depends on the crystallization conditions [33]. The mother lamellae, developed first, may lay edge- or flat-on at the reinforcement surface [34]. With the follow up development of daughter lamellae this results in a very complex structure. Accordingly, its load bearing capacity is direction dependent [17, 32]. Thus the interfacial shear strength data, usually determined, 


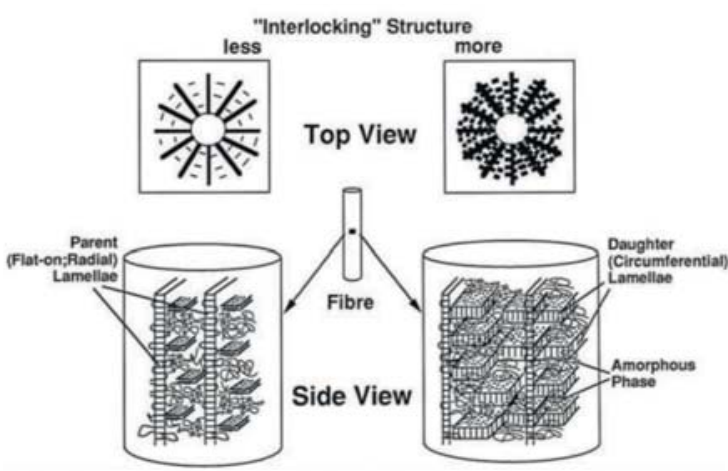

Figure 2: TC layer structure with improved stress transfer capability via lamellar interlocking and amorphous phase promoted adhesion.

may differ from the transverse ones. A further implication arises from the relaxing tape or fiber used as reinforcements in SPCs. Their relaxation through shrinkage generates a local shear flow in the crystallizing melt. This is the cause of the appearance of cylindritic superstructure. By contrast to $\mathrm{TC}$, the cylindrite is created through homogenous nucleation [35]. Furthermore, the wetting of the reinforcement by the matrix should be considered, too. Wetting is facilitated by amorphous polymers in traditional thermoplastic matrix-based composites as shown on the example of aPP/glass fiber [36]. Based on the above aspects Karger-Kocsis [37] recommended an optimum TC layer structuring: lamellar interlocking and amorphous adherent. This structure should have not only improved interfacial bonding, but being quasi isotropic, less sensitive to the loading direction (cf. Figure 2).

Efforts were made to improve the interfacial strength in SPCs by other means than transcrystallization. Ratner et al. [38] combined the hot compaction of UHMWPE fibers with in situ peroxide initiated crosslinking. Bhattacharyya et al. [39-40] triggered transreactions, more exactly transamidation to improve the interfacial properties of PA6-based SPCs.

\section{Production, Characteristics}

Albeit there are many possibilities to produce SPC, industrially three of them have been practiced so far. They use different performs, -fabricates as shown below.

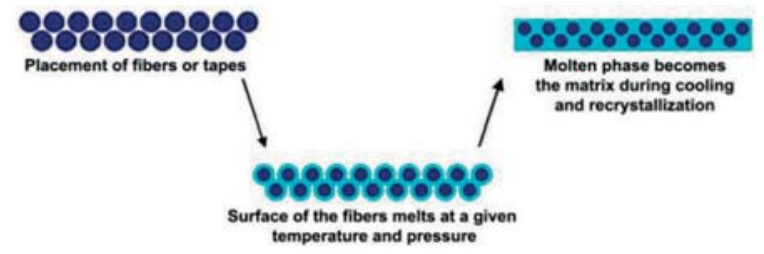

Figure 3: Principle of hot compaction schematically.

\subsection{Hot compaction}

During hot compaction different assemblies of fibres or tapes are compacted at a temperature within the melting range, more exactly in the vicinity of the melting onset of the fibers. A certain proportion of surface of each fiber melts which upon cooling, solidifies and binds the structure together (cf. Figure 3). So, the molten portion of the fiber volume forms the matrix of the composite ([22-23] and references therein)]. It is obvious that this technique makes use of the broad melting range of semicrystalline polymers and the overheating phenomenon because the prefabricate, to be consolidated, is under constraints (tensile/compression). It is worth of noting that hot compaction may result in final products, as well [41]. Hot compaction has been well explored for many different polymers and corresponding fabric systems. Moreover, hot compacted prefabricates are produced commercially (e.g. Curv $\left.{ }^{\circledR}\right)$.

\subsection{Coextrusion}

Bicomponent tapes with skin/core/skin cross section may be fabricated by coextrusion. The skin layer is composed of a copolymer with lower $\mathrm{T}_{\mathrm{m}}$ than the homopolymer core material. Accordingly, the copolymer skin overtakes the role of the matrix during hot pressing, whereas the remaining core acts as reinforcement. The coextrusion techniques involve a stretching, drawing step to achieve the required stiffness and strength for the reinforcing constituent [42-44] - cf. Figure 4. The beauty of this production method is that the reinforcement content (i.e. core layer) is very high (>80\%) and it is well preserved during processing. Bicomponent tapes are available under the trade names Pure ${ }^{\circledR}$, Armordon ${ }^{\circledR}$. They are processed in tape form or as fabrics with various weaving patterns via compression molding, vacuum bagging, hot stamping, thermoforming, and tape winding [44-46]. 


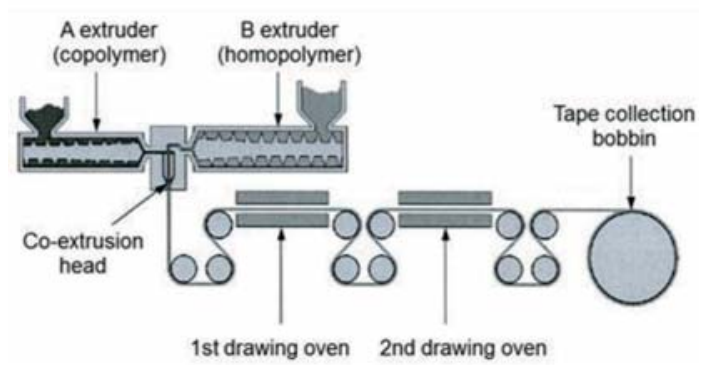

Figure 4: Scheme of the production of bicomponent, stretched tape $\left(\right.$ Pure $\left.^{\circledR}\right)$.

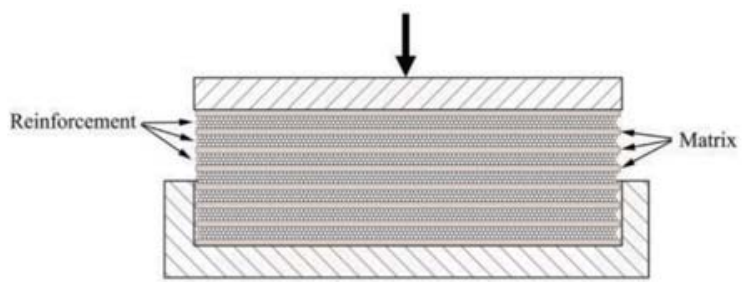

Figure 5: Scheme of the film stacking.

\subsection{Film stacking}

During film stacking the reinforcing fabrics are "sandwiched" in between films-cf. Figure 5. The films are formed either from copolymers or homopolymers with quenching in order to guarantee the necessary temperature window during hot pressing. As reinforcing fabrics usually woven fabrics from tapes or fibers of highly oriented and crystalline homopolymers are used. PET-based SPCs [47] are produced by this technique from fabrics composed of commingled yarns by Wah Hong Industrial Co. (Taiwan). It has to be mentioned that some of the above techniques may be combined. For example hot compaction can be combined with film stacking. Hine et al. [48] studied this interleaving method in order to reach a better balance in the mechanical properties and a wider temperature window for processing.

\section{Reprocessing}

SPCs are referred to materials of "ultimate" recycling. Interestingly, this aspect was less studied. Recycling via remelting of SPCs was mostly studied in repeated injection molding. On the other hand, the works performed on this field [49] clearly show that the number of reprocessing/remelting cycles which is not accompanied with property deterioration agree fairly with the related value, known for injection moldable grade.

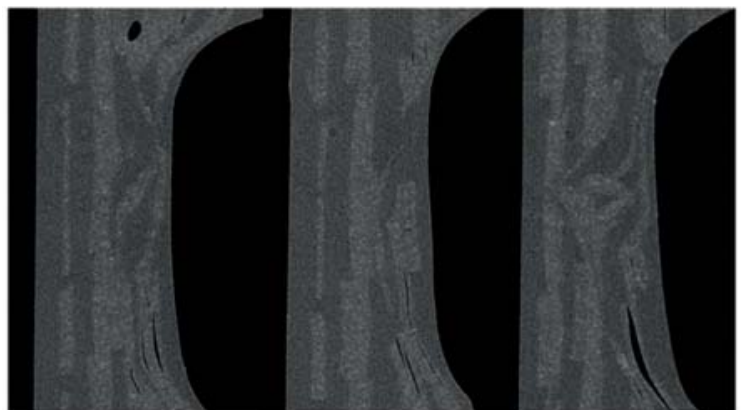

Figure 6: Two-dimensional (2D) frames of the ultrasonic welding seam in a PP-based SPC assessed by X-ray micro computed tomography. Notes: pictures from left to right were taken at increasing depth of the seam; the thickness of the seam is about $1 \mathrm{~mm}$.

\section{Outlook and Future Trends}

SPCs are still in focus of interest due to their low density and ultimate recycling. From the matrix side attempts will be made to widen the processing window by making use of polymorphism and copolymerization techniques. The reinforcements, still remaining in fiber and tape forms, will probably be strengthened by nanofillers, especially by those which have high aspect ratios.

SPCs of more complex structure, such as panels containing honeycomb or foam cores, may help to acquire new applications fields [50]. Their fire resistance will be improved. This is a high priority issue for many further potential applications. Pioneering activity in this direction yielded some peculiar results [51-52]. A further hot topic is the development of (multi) functional SPCs which show for example shape memory performance [53] or phase change behavior [54]. In case of hot pressing of non-consolidated preforms trials will be done to avoid problems with the "slow" heat conductivity. Incorporation of suitable (nano) particles in the matrix or matrix-giving component acting as hot spots (heat sources) by external triggering (electromagnetic field, microwave etc.) seems to be a sound strategy [55]. Similarly, consolidation with molds guaranteeing extreme fast heating and cooling, such as Rocktool ${ }^{\circledR}$, will gain in importance.

The most challenging question with SPCs is whether injection moldable grades can be produced. The first steps in this direction has been done making use of the copolymer(matrix)/homopolymer (fiber 
reinforcement) strategy [56-57].

Welding of SPC parts is a further open issue. For that purpose ultrasonic and friction stir type welding versions [58-59] seem to be suitable. For the quality assurance of the SPC parts non-destructive techniques should be developed. Note that the acoustic emission methods, adapted so far [60-61], can be treated only as quasi non-destructive one. In this respect, tomography techniques may be the winners-cf. Figure 6 .

Adequate modeling of the structure-property relationships in SPCs is a further task to be solved [62].

\section{References}

[1] Á. Kmetty, T. Bárány, and J. Karger-Kocsis, "Self-reinforced polymeric materials: A review," Prog Polym Sci, vol. 35(10), pp. 1288-1310, 2010.

[2] C.C.Gao,L.Yu,H.S.Liu, andL.Chen, "Development of self-reinforced polymer composites," Prog Polym Sci, vol. 37(6), pp. 767-780, 2012.

[3] S. Fakirov, "Nano- and Microfibrillar SinglePolymer Composites: A Review," Macromol Mater Eng, vol. 298(1), pp. 9-32, 2013.

[4] K.P. Matabola, A.R. De Vries, F.S. Moolman, and A.S. Luyt, "Single polymer composites: a review," J Mater Sci, vol. 44(23), pp. 6213-6222, 2009.

[5] J. Karger-Kocsis and S. Fakirov, "Polymorphismand stereoregularity-based single polymer composites," In: Synthetic Polymer-Polymer Composites, (Bhatracharyya D. and Fakirov S., eds.), Carl Hanser Verlag, Munich, 2012, pp. 673-698.

[6] N.J. Capiati and R.S. Porter, "Concept of one polymer composites modeled with high-density polyethylene," J Mater Sci, vol. 10(10), pp. 1671-1677, 1975.

[7] N.D. Jordan, D.C. Bassett, R.H. Olley, P.J. Hine, and I.M. Ward, "The hot compaction behaviour of woven oriented polypropylene fibres and tapes. II. Morphology of cloths before and after compaction," Polymer, vol. 44(4), pp. 1133-1143, 2003.

[8] D. Yao, R.H. Li, and P. Nagarajan, "Singlepolymer composites based on slowly crystallizing polymers," Polym Eng Sci, vol. 46(9), pp. 1223-1230, 2006.

[9] R.H Li and D.G. Yao, "Preparation of single poly(lactic acid) composites," J Appl Polym Sci, vol. 107(5), pp. 2909-2916, 2008.
[10] P. Dai, W. Zhang, Y.T. Pan, J.N. Chen, Y.J Wang, and D.G. Yao, "Processing of single polymer composites with undercooled polymer melt," Compos Part B-Eng, vol. 42(5), pp. 1144-1150, 2011.

[11] M. Harsch, J. Karger-Kocsis, and A.A. Apostolov, "Crystallization-induced shrinkage, crystalline, and thermomechanical properties of in situ polymerized cyclic butylene terephthalate," J Appl Polym Sci, vol. 108(3), pp. 1455-1461, 2008.

[12] Z.A.M Ishak, K.G. Gatos, and J. Karger-Kocsis, "On the in-situ polymerization of cyclic butylene terephthalate oligomers: DSC and rheological studies," Polym Eng Sci, vol. 46(6), pp. 743-750, 2006.

[13] J. Karger-Kocsis and L. Kiss, "Attempts of separation of the polymerization and crystallization processes by means of DSC thermograms of activated anionic-polymerization of epsiloncaprolactam," Makromol Chem, vol. 180(6), pp. 1593-1597, 1979.

[14] L. Kiss and J. Karger-Kocsis, "DSC investigations on the alkaline polymerization of epsiloncaprolactam," J Therm Anal, vol. 19(1), pp. 139-141, 1980.

[15] N.Dencheva,Z.Denchev,A.S.Pouzada,A.S.Sampaio, and A.M. Rocha, "Structure-properties relationship in single polymer composites based on polyamide 6 prepared by in-mold anionic polymerization," J Mater Sci, vol. 48(20), pp. 7260-7273, 2013.

[16] N. Barhoumi, A. Maazouz, M. Jaziri, and R. Abdelhedi, "Polyamide from lactams by reactive rotational molding via anionic ringopening polymerization: Optimization of processing parameters," Express Polym Lett, vol. 7(1), pp. 76-87, 2013.

[17] J. Karger-Kocsis, Polypropylene: An A-Z Reference, Dordrecht: Kluwer Publishers, 1999.

[18] J. Karger-Kocsis, Polypropylene: Structure, Blends and Composites, London: Chapmann and Hall, vol. 1-3, 1995.

[19] M. Gahleitner, "Controlling properties by understanding polymer crystallization," Express Polym Lett, vol. 7(11), pp. 885, 2013.

[20] J. Karger-Kocsis, "Composite composed of polypropylene reinforcement and polypropylene matrix and various production methods thereof," German patent, DE 10237803 B4, 2007. 
[21] J. Varga, "Beta-modification of isotactic polypropylene: Preparation, structure, processing, properties, and application," J Macromol Sci Phys, vol. 41(4-6), pp. 1121-1171, 2002.

[22] I.M. Ward, "Developments in oriented polymers, 1970-2004," Plast Rubber Compos, vol. 33(5), pp. 189-194, 2004.

[23] P.J. Hine and I.M. Ward, "High stiffness and high impact strength polymer composites by hot compaction of oriented fibers and tapes, in Mechanical Properties of Polymers based on Nanostructure and Morphology," In: Mechanical properties of polymers based on nanostructure and morphology, (Baltá-Calleja F.J. and Michler G.H., eds.), Boca Raton: CRC Press, 2005, pp. 677-698.

[24] R.H. Kok and H. Grunstra, "Co-extruded tape or yarn," European patent application, EP 0776762A1, 1996.

[25] N.M. Barkoula, T. Peijs, T. Schimanski, and J. Loos, "Processing of single polymer composites using the concept of constrained fibers," Polym Composite, vol. 26(1), pp. 114-120, 2005.

[26] W.H. Ruan, T. Czigány, T. Bárány, M.Z. Rong, and M.Q. Zhang, "Layered polymer-polymer composites with nanocomposite as reinforcement," In: Synthetic Polymer-Polymer Composites, (Bhatracharyya D. and Fakirov S., eds.), Carl Hanser Verlag, Munich, 2012, pp. 699-718.

[27] P. Hine, V. Broome, and I. Ward, "The incorporation of carbon nanofibres to enhance the properties of self reinforced, single polymer composites," Polymer, vol. 46(24), pp. 10936-10944, 2005.

[28] S. Fakirov, "The concept of micro- or nanofibrils reinforced polymer-polymer composites," In: Synthetic Polymer-Polymer Composites, (Bhatracharyya D. and Fakirov S., eds.), Munich: Carl Hanser Verlag, 2012, pp. 353-400.

[29] J. Loos, T. Schimanski, J. Hofman, T. Peijs, and Lemstra P.J., "Morphological investigations of polypropylene single-fibre reinforced polypropylene model composites," Polymer, vol. 42(8), pp. 3827-3834, 2001.

[30] H. Quan, Z.M. Li, M.B. Yang, and R. Huang, "On transcrystallinity in semi-crystalline polymer composites," Compos Sci Technol, vol. 65(7-8) pp. 999-1021, 2005.

[31] H. Ishida and P. Bussi, "Morphology Control in Polymer Composites," In: Materials Science and Technology, (Chou T.W., ed.), Weinheim: VCH, 1993, vol. 13, pp. 339-379.

[32] H.J. Kestenbach, J. Loos, and J. Petermann, "Transcrystallization at the interface of polyethylene single-polymer composites," Mater Res, vol. 2, pp. 261-269, 1999.

[33] C.M. Wu, M. Chen, and J. Karger-Kocsis, "The role of metastability in the micromorphologic features of sheared isotactic polypropylene melts," Polymer, vol. 40(15), pp. 4195-4203, 1999.

[34] A. Lustiger, C.N. Marzinsky, R.R. Mueller, and HD. Wagner, "Morphology and damage mechanisms of the transcrystalline interphase in polypropylene," J Adhesion, vol. 53(1-2), pp. 1-14, 1995.

[35] J. Varga and J. Karger-Kocsis, "Rules of supermolecular structure formation in sheared isotactic polypropylene melts," J Polym Sci Pol Phys, vol. 34(4), pp. 657-670, 1996.

[36] F. Hoecker and J. Karger-Kocsis, "On the effects of processing conditions and interphase of modification on the fiber/matrix load transfer in single fiber polypropylene composites," J Adhesion, vol. 52(1-4), pp. 81-100, 1995.

[37] J. Karger-Kocsis, "Interphase with lamellar interlocking and amorphous adherent-A model to explain effects of transcrystallinity," Adv Compos Lett, vol. 9(3), pp. 225-227, 2000.

[38] S. Ratner, A. Weinberg, and G. Marom, "Morphology and mechanical properties of crosslinked PE/PE composite materials," Polymer Compos, vol. 24(3), pp. 422-427, 2003.

[39] S. Fakirov, Transreactions in Condensation Polymers, Weinheim: Wiley-VCH, 1999.

[40] D. Bhattacharyya, P. Maitrot, and S. Fakirov, "Polyamide 6 single polymer composites," Express Polym Lett, vol. 3(8), pp. 525-532, 2009.

[41] W. Prosser, P.J. Hine, and I.M. Ward, "Investigation into thermoformability of hot compacted polypropylene sheet," Plast Rubber Compos, vol. 29(8), pp. 401-410, 2000.

[42] B. Alcock, N.O. Cabrera, N.M. Barkoula, J. Loos, and T. Peijs, "The mechanical properties of unidirectional all-polypropylene composites," Compos Part a-Appl S, vol. 37(5), pp. 716-726, 2006.

[43] B. Alcock, N.O. Cabrera, N.M. Barkoula, A.B. Spoelstra, J. Loos, and T. Peijs, "The 
mechanical properties of woven tape allpolypropylene composites," Compos Part a-Appl S, vol. 38(1), pp. 147-161, 2007.

[44] T. Peijs, "Composites for recyclability," Mater Today, vol. 6(4), pp. 30-35, 2003.

[45] N. Cabrera, B. Alcock, J. Loos, and T. Peijs, "Processing of all-polypropylene composites for ultimate recyclability," Proc Inst Mech Eng Pt L-J Mater-Design Appl, vol. 218(L2), pp. 145-155, 2004.

[46] B. Alcock, N. Cabrera, N. Barkoula, and T. Peijs, "Direct forming of all-polypropylene composites products from fabrics made of co-extruded tapes," Appl Compos Maters, vol. 16(2), pp. 117-134, 2009.

[47] J.C. Chen, C.M. Wu, F.C. Pu, and C.H. Chiu, "Fabrication and mechanical properties of selfreinforced poly(ethylene terephthalate) composites," Express Polym Lett, vol. 5(3), pp. 228-237, 2011.

[48] P.J. Hine, R.H. Olley, and I.M. Ward, 2008. "The use of interleaved films for optimising the production and properties of hot compacted, self reinforced polymer composites," Compos Sci Technol, vol. 68(6), pp. 1413-1421.

[49] T. Bárány, A. Izer, and A. Menyhárd, "Reprocessability and melting behaviour of self-reinforced composites based on PP homo and copolymers," $J$ Therm Anal Calorim, vol. 101(1), pp. 255-263, 2010.

[50] N.O. Cabrera, B. Alcock, and T. Peijs, "Design and manufacture of all-PP sandwich panels based on co-extruded polypropylene tapes," Compos Part B-Eng, vol. 39(7-8), pp. 1183-1195, 2008.

[51] K. Bocz, T. Bárány, A. Toldy, B. Bodzay, I. Csontos, K. Madi, and G. Marosi, "Selfextinguishing polypropylene with a mass fraction of $9 \%$ intumescent additive-A new physical way for enhancing the fire retardant efficiency," Polym Degrad Stabil, vol. 98(1), pp. 79-86, 2013.

[52] K. Bocz, A. Toldy, A. Kmetty, T. Bárány, T. Igricz, and G. Marosi, "Development of flame retarded self-reinforced composites from automotive shredder plastic waste," Polym Degrad Stabil, vol. 97(3), pp. 221-227, 2012.
[53] I.S. Kolesov, H.J. Radusch, "Multiple shapememory behavior and thermal-mechanical properties of peroxide cross-linked blends of linear and short-chain branched polyethylenes," Express Polym Lett, vol. 2(7), pp. 461-473, 2008.

[54] AS. Luyt, "Recent research on conductive phase change materials for energy storage," Express Polym Lett, vol. 7(4), pp. 319-319, 2013.

[55] T. Bayerl, M. Duhovic, P. Mitschang, and D. Bhattacharyya, "The heating of polymer composites by electromagnetic induction," Compos Part a-Appl S, in press.

[56] A. Kmetty, T. Bárány, and J. Karger-Kocsis, "Injection moulded all-polypropylene composites composed of polypropylene fibre and polypropylene based thermoplastic elastomer," Compos Sci Technol, vol. 73, pp. 72-80, 2012.

[57] A. Kmetty, T. Tábi, J.G. Kovács, and T. Bárány, "Development and characterisation of injection moulded, all-polypropylene composites," Express Polym Lett, vol. 7(2), pp. 134-145, 2013.

[58] Z. Kiss and T. Czigány, "Microscopic analysis of the morphology of seams in friction stir welded polypropylene," Express Polym Lett, vol. 6(1), pp. 54-62, 2012.

[59] Z. Kiss, Á. Kmetty, and T. Bárány, "Investigation of the weldability of the slef-reinforced polypropylene composites," Materials Sci Forum, vol. 659, pp. 25-30, 2010.

[60] G. Romhány, T. Bárány, T. Czigány, and J. Karger-Kocsis, "Fracture and failure behavior of fabric-reinforced all-poly (propylene) composite (Curv (R))," Polym Advan Technol, vol. 18(2), pp. 90-96, 2007.

[61] A. Izer, A. Stocchi, T. Bárány, V. Pettarin, C. Bernal, and T. Czigány, "Effect of the consolidation degree on the fracture and failure behavior of self-reinforced polypropylene composites as assessed by acoustic emission," Polym Eng Sci, vol. 50(11), pp. 2106-2113, 2010.

[62] S. Houshyar, R.A. Shanks, and A. Hodzic, "Modelling of polypropylene fibre-matrix composites using finite element analysis," Express Polym Lett, vol. 3(1), pp. 2-12, 2009. 